\title{
EVALUATION OF THE IMPACT OF AN AWARENESS-BASED ANIMATION ON STUDENTS' KNOWLEDGE ABOUT MENTAL ILLNESS
}

\author{
Mojca Plot ${ }^{1}$ (D), Saška Roškar ${ }^{2}$ (D), Helena Gabrijelčič Tomc ${ }^{1}$ (D) \\ ${ }^{1}$ University of Ljubljana, Faculty of Natural Sciences and Engineering, Department of Textiles, \\ Graphic Arts and Design, Chair of Information and Graphic Arts Technology, Ljubljana, Slovenia \\ ${ }^{2}$ National Institute of Public Health, Ljubljana, Slovenia
}

\begin{abstract}
Animation is an exceptionally good medium for educating and raising awareness of the issues that are more difficult to talk about, such as mental illness. The use of animation and graphics in society awareness and education can improve knowledge and communication about issues related to mental illness. Despite various destigmatization activities, people are still reluctant to directly approach individuals suffering from mental illness, partly because they do not have enough knowledge on the subject. Therefore, the aim of our study was to test whether animation can improve the knowledge about appropriate / inappropriate conversations with a person suffering from depression in a Slovenian student population. We focused on education and awareness-based animation (adapted to the target group) to evoke empathy without arousing pity and to indirectly encourage people in need and others to talk about it. The methodology included the surveying of the participants and their knowledge about appropriate and inappropriate conversations with a person suffering from depression (22 phrases, 11 appropriate and 11 inappropriate). 251 participants aged 19 to 30 completed the survey. Participants were asked to rate each phrase for appropriateness on a 5-point Likert scale before and after being exposed to the animation. The results obtained were analysed using the paired samples t-test. The desired change in knowledge was confirmed by comparing the average scores of the survey responses before and after viewing the animation. A statistically significant result was obtained in 18 of 22 sentences. A change in the desired direction was detected in $81 \%$ of the statements. Our study had some limitations, but we nevertheless conclude that an awareness-based animation can be a useful tool to increase knowledge and subsequently influence behavioural change in the student population.
\end{abstract}

Key words: illustration, animation, stigma, mental disorders, depression

\section{INTRODUCTION}

Web videos or animations are an effective medium for raising awareness, as the ability to remember a message is $58 \%$ higher than when information is provided with an audio clip alone. Recipients of an animated message are more likely to receive and remember the message, and they are also more likely to receive the message faster because the animated message is usually accessible on variable devices (Instruxion, 2014). Yamaguchi et al (2013), in a systematic review of student-centred anti-stigmatism programs, found that video and face-to-face contact are the most effective means of intervention to change attitudes and reduce social distance (Yamaguchi et al, 2013).

The word "stigma" had sometimes been used to denote physical signs that have been cut or burned into the body of a violated person (Goffman, 2008). Today we understand stigma as a social psychological construct that refers to stereotypes, prejudice and discrimination (Pregelj et al, 2013). Stereotypes are apparently well-founded facts (Corrigan and Bink, 2016) that correctly or incorrectly generalize social phenomena, social groups and their members. Stereotypes develop into prejudices when people have negative feelings towards stereotyped people and evaluate them negatively (Corrigan and Bink, 2016). While prejudice is the emotional reaction of an individual to the object of stigmatization, discrimination refers to a behavioural response (different treatment of people) (Corrigan and Bink, 2016). Due to stigma, people with mental disorders do not seek help in time or not at all. Research shows that there is a link between the symptoms of mental illness and adolescence (Pregelj et al, 2013).

The first symptoms of mental illness plaguing adults develop by the mid-twenties. In individuals with mood disorders, $25 \%$ develop the disorder by the age of 18 , anxiety disorders develop by $75 \%$ by the age of 21 , and $75 \%$ of people with a mental disorder develop it by the age of 24 . Studies show that undergraduate students often have mental health problems, but most often do not seek help (Gaddis et al, 2018). Based on the results of a study by Calear et al (2019), which examined the personal and public stigmatisation of depression in Australian youth, it would be useful to develop a general campaign to 
reduce the stigma of youth and a specific campaign to reduce the stigma of young men who have little experience and knowledge of depressive disorders.

In a study (Vidourek and Burbage, 2019) on positive mental health and the stigma of mental health among students, the researchers equated positive mental health with happiness, low stress and a positive attitude. Improved quality of life, better coping with problems and reduced stress were described as positive treatment benefits. In this study, students recognized the benefits of seeking help. By being aware of the perceived benefits and highlighting them, barriers to treatment can be removed as students would have a more acceptable attitude towards seeking treatment for mental health problems. The study found that most students believe that stigma is an obstacle to treatment. They also believe that the search for help needs to be intensified, which can be achieved by reducing stigmatization through education and understanding. A few participants pointed out that media coverage of mental health influences society's perception of what it means to have mental health problems. Education and awareness were identified as key factors in reducing stigma and increasing treatment rates.

People find it easier to identify with a message created by focusing on a specific group of people (Gauss, 2020). The campaign message should be designed so that people can easily understand it. People must be given a clear message that their participation has a positive impact (Esquivel, 2020). The audience is likely to attribute a high level of credibility if they have first-hand experience of the topic; people are also more receptive to resources that are similar to them and embody characteristics such as sympathy, professionalism and trust (Yamaguchi et al, 2013).

The structure and content of a message influences attention, perception, emotions, and intentions. When creating a message, the creator can attract the attention of the audience, improve the memory of the message and trigger emotional reactions by using structural characteristics that function in accordance with people's cognitive and physiological processes. When designing audio and video messages, the audience can be directed to focus on specific moments and specific content by creating messages with structural characteristics that trigger targeted reactions (Yamaguchi et al, 2013). Social marketing is a way to raise interest in the plight of disadvantaged groups and motivate others to take collective action (Summers and Summers, 2017). For communication it uses visual elements that evoke empathy (Grinstein et al, 2019). Because of empathy, the consumers of the message have positive feelings towards stigmatized persons and an increased need for help (Summers and Summers, 2017). Empathy requires identification and perceived need (Grinstein et al, 2019). In a study of the effects of pity on the perception of oneself and other mentally ill people, Fominaya et al (2016) found that pity not only reduces anger but also increases avoidance. The findings of this research were consistent with the model of self-stigmatization, which states that perceived stigmatization is the first step to self-stigmatization. Moreover, the findings suggest that programs meant to remove the stigma of mental illness should avoid messages that pose mental illness in a pitying light.

The purpose of the presented research was to study the factors influencing the message, comprehensibility and effectiveness of 2D illustration and animation, and on the basis of this study to create an animation that provides a good insight into the plight of a person with depression and teaches appropriate and inappropriate communication talking to a person with depression and emphasizing the importance of proper support. In the research, our goal was to prove that watching visual animated images and listening to the phrases (sentences) that are more or less suitable for communication with a person suffering from depression can improve the understanding of the plight of the person suffering from depression and awareness about which phrases are suitable and not suitable in communicating. We hypothesized that after watching the animation with the goal of teaching about appropriate and inappropriate communication with a person with depression, the percentage of sentences that the respondents of the questionnaire would label as suitable for communication with a person with depression would change.

\section{METHODS}

The methodology included the identification of the target group, animation production, the testing of the participants (target group representatives) and the statistical analysis of the results.

The target group were students of the 1st and 2 nd level of higher and university educational study programme of the University of Ljubljana (study programmes of different professional fields). Animation production included: 
- pre-production of animation: determining the message of the animation, writing the script, and creating the story (narrative in the form of a personal confession of the student)

- production and post-production of animation: digital illustration - XP-PEN Artist 22E Pro graphics tablet and Adobe Photoshop CC 2018; sound and narration capture - microphone and Audacity program; illustration animation - Adobe After Effects CC 2018; and editing - Adobe Premiere Pro CC 2018.

The survey of the target group was conducted using the Google Forms tool, and an anonymous survey was sent by e-mail. The online survey was divided into three parts:

- Part 1 of the survey: the participants filled in demographic data, answered a question whether they had personal experiences with a mental disorder and completed a questionnaire consisting of 22 phrases (11 suitable and 11 unsuitable for communicating with a person with depression).

- Part 2 of the survey: The participants watched the animation.

- Part 3 of the survey: Participants answered a questionnaire consisting of 22 phrases with 11 appropriate and 11 inappropriate phrases in communication with a person with depression (the distribution of phrases was different from part 1 of the test), from which participants had to choose phrases again that they thought were appropriate for communication with a person with depression.

- Examples of inappropriate phrases were: "You do not look depressed to me", "Try to get more exercise and eat a healthy diet", "Get yourself together. Be grateful for what you have. "Ah, you do not have to be depressed about anything. You've got it all.", etc., and examples of appropriate phrases: "I am worried about you. Is there anything I can do to help you? "," Whenever you want to share something with me, I am here for you. I am interested in everything you want to tell me. "," I am here for you even in difficult times. I am not going anywhere. "," I want to help you. You are not alone.", etc.

- Each sentence was rated by the participants on a 5-point Likert scale (1 - totally inappropriate; 2 - slightly appropriate, 3 - I do not know; 4 - quite appropriate; 5 - totally appropriate) and marked as appropriate or inappropriate.

The statistical analysis of the results was performed in IBM SPSS Statistics. We were interested in whether the percentage of responses indicating inappropriate communication with a person suffering from depression changes after watching the animation. The mutual comparison of the average values of the selected parameters (the degree of suitability of the sentence) was performed with a paired sample t-test for repeated measurements, i.e. evaluation of the survey responses in twenty-two sentences before and after watching the animation. The value of statistical significance was defined at $p=0.05$; with a confidence interval of $95 \%$. The change in attitude to a more or less appropriate phrase was characterized by a positive or negative difference calculated between the responses resulted before and after watching the animation. If defined statistical conditions were met, it could be argued that the person's attitude has changed, which meant that there had been a relevant change in knowledge about the topic. The relevant change has been confirmed when the response was statistically significant, i.e. in the respondent attitude there was a change to more appropriate or less stigmatizing phrase to address a person with depression.

\section{RESULTS}

Figure 1 shows scenes from the animation, which depicts the personal experience of a student with depression and the support she receives from her environment. The main message is that depression is a curable disease, so the animation urges people to support people, not stigmatise them.

The total number of respondents who filled out the entire survey was 251 . Their age was between 19 and 30 years old (Figure 2a). All questions in the survey were mandatory, so that participants could only submit a fully completed survey. Significantly more women than men took part in the survey, namely 218 women and 33 men. There were several possible answers to the question "Do you have any experience with a mental disorder?". 269 answers were recorded (Figure 2b), indicating that the participants had a personal experience with a mental disorder or knew someone who had an experience with a mental disorder. The participants ticked 86 times that they had no experience with the mental disorder or did not want to say that they had. 


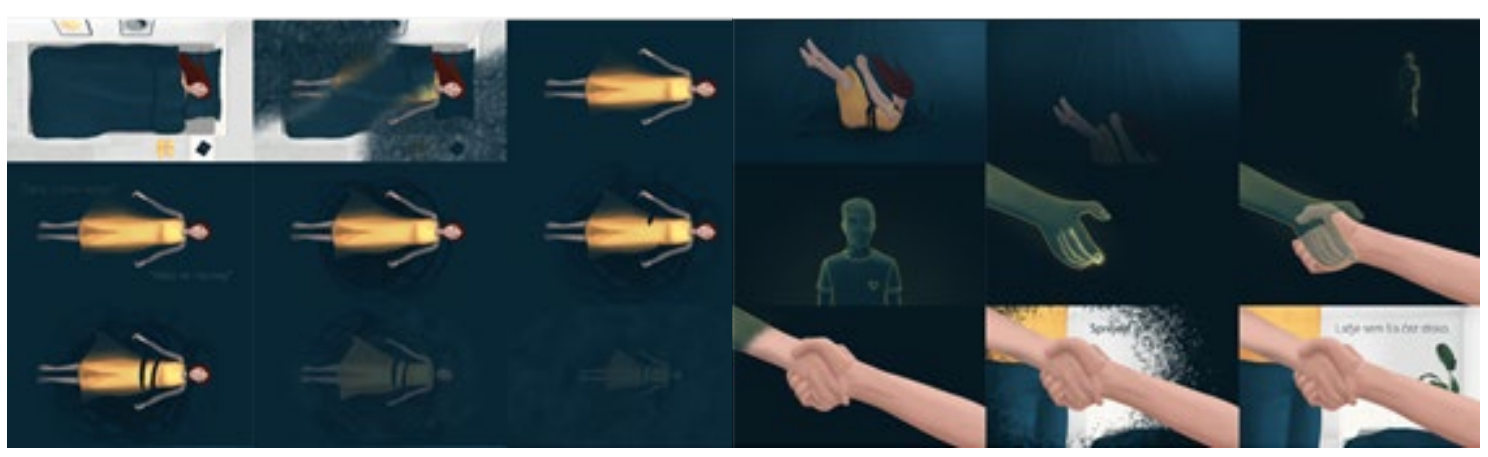

Figure 1: Final animation plans

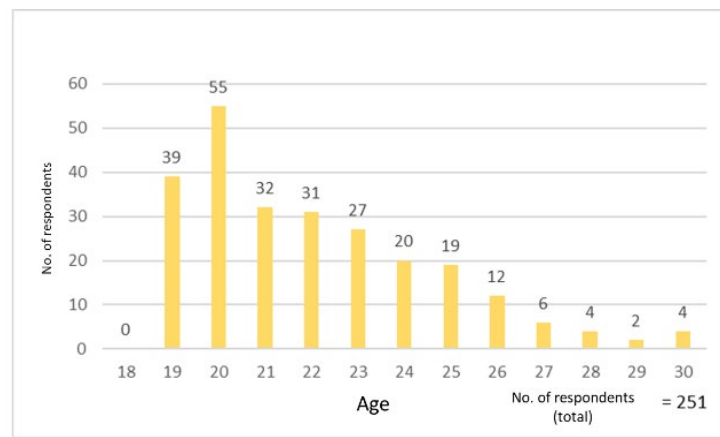

a)

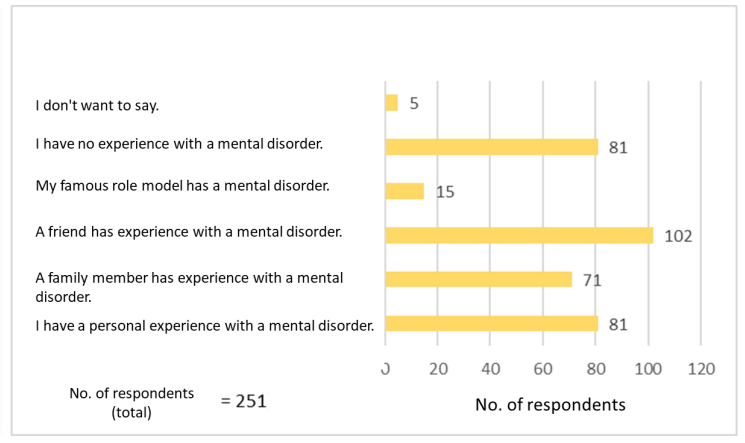

b)

Figure 2: Age structure of respondents and number of respondents who had or did not have experience with a mental disorder

\subsection{Statistical analysis}

The analysed data of the selection of 22 appropriate and inappropriate phrases are presented in Table 1 as mean values and standard errors (SN). The mutual comparison of the mean values of the selected parameters (the degree of suitability of the phrase) was performed with a Paired Sample T-Test for repeated measurements. We used it to evaluate the survey responses in twenty-two sentences before and after watching the animation. Table 1 contains descriptive statistics. The mean values of the answers of all sentences before and after watching the animation and the standard deviation are calculated.

Table 1 (part 1): Descriptive statistical values of the sentences used in both measurements. The letter B indicates the answers before watching the animation and the letter $A$ indicates the answers after watching the animation

\begin{tabular}{|c|c|c|c|c|}
\hline $\begin{array}{c}\text { No. of } \\
\text { phrase }\end{array}$ & $\begin{array}{c}\text { Survey before / after } \\
\text { animation }\end{array}$ & $\begin{array}{c}\text { M - average response } \pm \\
\text { SN }\end{array}$ & N- No. of participants & $\begin{array}{c}\text { SD - standard } \\
\text { deviation }\end{array}$ \\
\hline 1 & B01 & $1,48 \pm 0,048$ & 251 & 0,766 \\
\hline \multirow{2}{*}{2} & A01 & $1,26 \pm 0,040$ & 251 & 0,641 \\
\hline \multirow{2}{*}{3} & B02 & $1,48 \pm 0,048$ & 251 & 0,761 \\
\hline \multirow{2}{*}{4} & A02 & $1,33 \pm 0,045$ & 251 & 0,713 \\
\hline \multirow{2}{*}{5} & B03 & $2,76 \pm 0,072$ & 251 & 1,139 \\
\hline 5 & A03 & $1,97 \pm 0,070$ & 251 & 1,115 \\
\hline & B04 & $1,44 \pm 0,049$ & 251 & 0,769 \\
\hline 6 & A04 & $1,22 \pm 0,036$ & 251 & 0,578 \\
\hline & B05 & $1,25 \pm 0,041$ & 251 & 0,647 \\
\hline & A05 & $1,13 \pm 0,030$ & 251 & 0,476 \\
\hline & B06 & $1,73 \pm 0,061$ & 251 & 0,970 \\
\hline
\end{tabular}


Table 1 (part 2): Descriptive statistical values of the sentences used in both measurements. The letter B indicates the answers before watching the animation and the letter $A$ indicates the answers after watching the animation

\begin{tabular}{|c|c|c|c|c|}
\hline $\begin{array}{l}\text { No. of } \\
\text { phrase }\end{array}$ & $\begin{array}{l}\text { Survey before / after } \\
\text { animation }\end{array}$ & $\begin{array}{c}\text { M - average response } \pm \\
\text { SN }\end{array}$ & $\mathrm{N}$ - No. of participants & $\begin{array}{l}\text { SD - standard } \\
\text { deviation }\end{array}$ \\
\hline \multirow[t]{2}{*}{7} & B07 & $1,61 \pm 0,062$ & 251 & 0,983 \\
\hline & A07 & $1,33 \pm 0,046$ & 251 & 0,735 \\
\hline \multirow[t]{2}{*}{8} & B08 & $2,14 \pm 0,073$ & 251 & 1,162 \\
\hline & A08 & $1,59 \pm 0,059$ & 251 & 0,940 \\
\hline \multirow[t]{2}{*}{9} & B09 & $1,29 \pm 0,040$ & 251 & 0,632 \\
\hline & A09 & $1,22 \pm 0,041$ & 251 & 0,648 \\
\hline \multirow[t]{2}{*}{10} & B10 & $2,05 \pm 0,068$ & 251 & 1,085 \\
\hline & A10 & $1,63 \pm 0,058$ & 251 & 0,917 \\
\hline \multirow[t]{2}{*}{11} & B11 & $1,31 \pm 0,041$ & 251 & 0,645 \\
\hline & A11 & $1,18 \pm 0,037$ & 251 & 0,583 \\
\hline \multirow[t]{2}{*}{12} & B12 & $4,27 \pm 0,057$ & 251 & 0,903 \\
\hline & A12 & $4,43 \pm 0,060$ & 251 & 0,958 \\
\hline \multirow[t]{2}{*}{13} & B13 & $4,46 \pm 0,050$ & 251 & 0,796 \\
\hline & A13 & $4,64 \pm 0,044$ & 251 & 0,692 \\
\hline \multirow[t]{2}{*}{14} & B14 & $4,54 \pm 0,048$ & 251 & 0,754 \\
\hline & A14 & $4,78 \pm 0,040$ & 251 & 0,629 \\
\hline \multirow[t]{2}{*}{15} & B15 & $4,73 \pm 0,037$ & 251 & 0,585 \\
\hline & A15 & $4,74 \pm 0,042$ & 251 & 0,670 \\
\hline \multirow[t]{2}{*}{16} & B16 & $4,56 \pm 0,045$ & 251 & 0,721 \\
\hline & A16 & $4,75 \pm 0,034$ & 251 & 0,547 \\
\hline \multirow[t]{2}{*}{17} & B17 & $4,05 \pm 0,061$ & 251 & 0,966 \\
\hline & A17 & $4,56 \pm 0,048$ & 251 & 0,759 \\
\hline \multirow[t]{2}{*}{18} & B18 & $4,55 \pm 0,044$ & 251 & 0,705 \\
\hline & A18 & $4,63 \pm 0,045$ & 251 & 0,705 \\
\hline \multirow[t]{2}{*}{19} & B19 & $4,35 \pm 0,052$ & 251 & 0,823 \\
\hline & A19 & $4,49 \pm 0,051$ & 251 & 0,812 \\
\hline \multirow[t]{2}{*}{20} & B20 & $4,15 \pm 0,060$ & 251 & 0,943 \\
\hline & A20 & $4,25 \pm 0,061$ & 251 & 0,967 \\
\hline \multirow[t]{2}{*}{21} & B21 & $4,18 \pm 0,054$ & 251 & 0,857 \\
\hline & A21 & $4,48 \pm 0,051$ & 251 & 0,802 \\
\hline \multirow[t]{2}{*}{22} & B22 & $4,64 \pm 0,044$ & 251 & 0,704 \\
\hline & A22 & $4,72 \pm 0,043$ & 251 & 0,683 \\
\hline
\end{tabular}

Table 2 shows the t-test values for repeated measurements (comparison of mean values before and after the animation) and the corresponding characteristic levels. As shown in Table 2, statistically significant differences occurred in 18 sentences out of 22 (1-8, 10-14, 16, 17, 19-21). 
Table 2: T-test values, comparisons of differences in mean values between the two measurements

\begin{tabular}{|c|c|c|c|c|c|}
\hline \multirow{2}{*}{$\begin{array}{l}\text { No. of the } \\
\text { phrase }\end{array}$} & \multirow[t]{2}{*}{$\mathrm{t}$} & \multirow{2}{*}{$\begin{array}{l}\mathrm{df} \text { - degree } \\
\text { of freedom }\end{array}$} & \multirow[t]{2}{*}{$\mathrm{p}$ - significance } & \multicolumn{2}{|c|}{$\mathrm{Cl}-95 \%$ confidence interval } \\
\hline & & & & lower & upper \\
\hline 1 & 5,076 & 250 & 0,000 & 0,134 & 0,304 \\
\hline 2 & 3,612 & 250 & 0,000 & 0,069 & 0,234 \\
\hline 3 & 11,306 & 250 & 0,000 & 0,648 & 0,922 \\
\hline 4 & 5,076 & 250 & 0,000 & 0,134 & 0,304 \\
\hline 5 & 3,284 & 250 & 0,001 & 0,046 & 0,185 \\
\hline 6 & 8,099 & 250 & 0,000 & 0,286 & 0,471 \\
\hline 7 & 5,452 & 250 & 0,000 & 0,181 & 0,385 \\
\hline 8 & 9,241 & 250 & 0,000 & 0,433 & 0,667 \\
\hline 9 & 1,635 & 250 & 0,103 & $-0,015$ & 0,158 \\
\hline 10 & 6,694 & 250 & 0,000 & 0,295 & 0,541 \\
\hline 11 & 4,016 & 250 & 0,000 & 0,069 & 0,202 \\
\hline 12 & $-2,400$ & 250 & 0,017 & $-0,283$ & $-0,028$ \\
\hline 13 & $-3,810$ & 250 & 0,000 & $-0,272$ & $-0,087$ \\
\hline 14 & $-5,520$ & 250 & 0,000 & $-0,324$ & $-0,154$ \\
\hline 15 & $-0,317$ & 250 & 0,751 & $-0,086$ & 0,062 \\
\hline 16 & $-5,141$ & 250 & 0,000 & $-0,264$ & $-0,118$ \\
\hline 17 & $-9,555$ & 250 & 0,000 & $-0,615$ & $-0,405$ \\
\hline 18 & $-1,882$ & 250 & 0,061 & $-0,179$ & 0,004 \\
\hline 19 & $-2,567$ & 250 & 0,011 & $-0,232$ & $-0,031$ \\
\hline 20 & $-2,031$ & 250 & 0,043 & $-0,204$ & $-0,003$ \\
\hline 21 & $-6,225$ & 250 & 0,000 & $-0,393$ & $-0,204$ \\
\hline 22 & $-1,952$ & 250 & 0,052 & $-0,168$ & 0,001 \\
\hline
\end{tabular}

\section{DISCUSSION}

The completion of the survey depended on people's willingness to participate and interest in the topic, as the survey was conducted online and was not mandatory. The link to the survey was distributed by email from various faculties and their social networks, so we could not predict how many women or men the survey would be forwarded to. Women suffer from depression twice as often as men (Dernovšek et al, 2006). Therefore, it is possible that they were more attracted to the topic and as a result participated in the survey more $(87 \%)$ than men $(13 \%)$.

By comparing the average values of the survey answers before and after watching the animation, we confirmed the change in knowledge about depression among students aged 19-30 years. The survey measured the participants knowledge of the appropriateness and inappropriateness of phrases that can be used in a conversation with a person suffering from depression. A statistically significant result was obtained for 18 of 22 sentences (1-8, 10-14, 16, 17, 19-21). If we convert this into percentages, we can conclude that the watching of the animation resulted in an $81.8 \%$ change in students thinking. The responses obtained from the survey indicate that the participants were able to correctly assess the appropriateness or inappropriateness of the sentences before watching the animation. Most of the participants had a personal experience with a mental disorder or know someone who had an experience with a mental disorder. According to the results, the animation further strengthened the participants' knowledge and convinced them of the appropriateness or inappropriateness of the sentences. This is indicated by lower averages of responses after watching the animation in sentences 1-11 and higher 
averages of responses after watching the animation in sentences $12-22$. The results after watching the animation were even closer to grade 1 - completely inappropriate, which is the desired result in sentences 1-11, or closer to grade 5 - completely appropriate, which is the desired result in sentences 1222. These results mean that the participants have understood the message of the animation. The message of the illustrations and the animation, in conjunction with the colour scheme and the narrative, was appropriate to convey the message and to raise awareness of the depression.

\section{CONCLUSIONS}

Mental disorders are diseases such as diabetes or various forms of cancer, but mental illnesses are much more stigmatized. One of the consequences of stigma is that it is difficult to seek help. Students often have mental health problems, but usually do not seek help (Gaddis et al, 2018). Campaigns that use the principles of social marketing are therefore important to combat the stigma of mental health problems, and they can use print and digital media, including animation, to present a variety of topics. Our aim was to use animation to introduce students to depression from the students' perspective, to teach them about appropriate and inappropriate communication that can be used in a conversation with a person with depression, and to demonstrate the importance of appropriate support.

We confirmed the hypothesis that animation is statistically relevant in changing students' beliefs about the appropriateness or inappropriateness of communication that can be used in a conversation with a person with depression, towards less stigma. A change in the desired direction was found in $81 \%$ of the claims. We found that animation as a visual and auditory stimulus had a positive effect on the change in thinking in students aged 19-30 years. Thus, the message of the illustrations and animations helped to facilitate understanding and awareness of depression, as we successfully conveyed the message to students, as the results of the survey show. By confirming the hypothesis, we proved the effectiveness of animation as an awareness-raising and educational material for presenting more difficult issues in destigmatisation campaigns. The survey showed that most people have a personal experience with a mental disorder or know someone who has experience with a mental disorder. With this in mind, the animation could be used as supporting material in a destigmatisation campaign, as it effectively presents the plight of a student with a depression and shows the right support or the importance of support from the environment and shows the acceptance of support as something positive. This would encourage discussion of more difficult issues between students and their families, which in turn could contribute to a greater search for or acceptance of help.

\section{REFERENCES}

[1] Calear, A. L., Griffiths, K. M., Christensen, H.: "Personal and perceived depression stigma in Australian adolescents: magnitude and predictors", Journal of Affective Disorders 129 (1-3), 104108, 2019. doi: 10.1016/j.jad.2010.08.019.

[2] Corrigan, P. W., Bink, A. B.: "The stigma of mental illness", Encyclopedia of Mental Health 4, 230234, 2016. doi: 10.1016/B978-0-12-397045-9.00170-1.

[3] Dernovšek, M. Z., Gorenc, M., Jeriček, H.: "Ko te strese stres: kako prepoznati in zdraviti stresne, anksiozne in depresivne motnje", (Inštitut za varovanje zdravja Republike Slovenije, Ljubljana, 2006.), page 54.

[4] Esquivel, M.: "How to start a standout awareness campaign", URL: https://www.wholewhale.com/tips/awareness-campaign-how-to/ (last request: 2020-07-02), 2020.

[5] Fominaya, A. W., Corrigan, P. W., Rüsch, N.: "The effects of pity on self- and other-perceptions of mental illness", Psychiatry Research 241, 159-164, 2016. doi: 10.1016/j.psychres.2016.04.058.

[6] Gaddis, S. M., Ramirez, D., Hernandez, E. L.: "Contextualizing public stigma: endorsed mental health treatment stigma on college and university campuses", Social Science \& Medicine 197, 183-191, 2018. doi: 10.1016/j.socscimed.2017.11.029.

[7] Gauss, A.: "A beginner's guide to scaling an awareness campaign", URL: https://www.classy.org/blog/a-beginners-guide-to-scaling-an-awareness-campaign/ (last request: 2020-07-02), 2020.

[8] Goffman, E.: "Stigma: Zapiski o upravljanju poškodovane identitete", (Založba Aristej, Maribor, 2008.), page 128. 
[9] Grinstein, A., Hagtvedt, H., Kronrod, A.: "Aesthetically (dis)pleasing visuals: a dual pathway to empathy and prosocial behavior", International Journal of Research Marketing 36 (1), 83-99, 2019. doi: 10.1016/j.ijresmar.2018.09.003.

[10] Instruxion: "How to use an animated video to create awareness of sensitive topics", URL: https://www.instruxion.com/how-to-use-an-animated-video-to-create-awareness-of-sensitivetopics/ (last request: 2020-04-02), 2014.

[11] Pregelj, P., Kores Plesničar, B., Tomori, M., Zalar, B., Ziherl, S.: “Psihiatrija”, (Psihiatrična klinika, Ljubljana, 2013.), pages 422-423.

[12] Summers, J., Summers, J.: "Motivating intention to take action on behalf of an out-group: implications for the use of advocacy messages in social marketing strategies", Journal of Marketing Management 33, 973-1002, 2017. doi: 10.1080/0267257X.2017.1311933.

[13] Vidourek, R. A., Burbage, M.: "Positive mental health and mental health stigma: a qualitative study assessing student attitudes", Mental Health \& Prevention 13, 1-6, 2019. doi: 10.1016/j.mhp.2018.11.006.

[14] Yamaguchi, S., Wu, S.-I., Biswas, M., Yate, M.: "Effects of Short-Term Interventions to Reduce Mental Health-Related Stigma in University or College Students A Systematic Review", The Journal of nervous and mental disease 201 (6), 490-503, 2013. doi: 10.1097/NMD.0b013e31829480df.

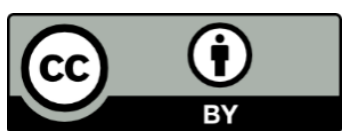

(C) 2020 Authors. Published by the University of Novi Sad, Faculty of Technical Sciences, Department of Graphic Engineering and Design. This article is an open access article distributed under the terms and conditions of the Creative Commons Attribution license 3.0 Serbia (http://creativecommons.org/licenses/by/3.0/rs/). 